\title{
Pulmonary Embolism-A Mechanical Compression Effect on Lower Limb Deep Venous Thrombosis
}

\author{
Annthea SW Lee ${ }^{1}$, Anne AL Hsu* \\ ${ }^{1}$ Yong Loo Lin School of Medicine, National University of Singapore, Singapore \\ ${ }^{2}$ Department of Respiratory \& Critical Care Medicine, Singapore General Hospital, Singapore
}

Keywords: Compression ultrasonography, Doppler sonography, Computed tomography of the thorax, Free-floating thrombus

Abbreviation: PE: Pulmonary Thromboembolism; DVT: Deep Vein Thrombosis; FFT: Free Floating Thrombus; CUS: Compression Ultrasonography; CT: Computed Tomography

\section{Introduction}

Majority of Pulmonary Thromboembolism (PE) results from clot fragmentation of lower limb Deep Venous Thrombosis (DVT) $[1,2]$. Non-invasive testing of the lower limb, such as Compression Ultrasonography (CUS), is the gold standard for the routine diagnosis of DVT. Free-Floating Thrombus (FFT) is present in $10-26 \%$ of thrombi detected with ultrasound and is often considered being a risk factor for PE in patients with DVT [3]. Few cases in which CUS may have dislodged a blood clot and caused a PE have been reported [4].

We present 3 cases (Table 1) of acute PE following mechanical compression effect on lower limb DVT.

\section{Case 1}

An 85 year-old man presented with 4-day history of progressively worsens dyspnea with bilateral lower limb edema. He also had cough productive of purulent sputum and hemoptysis. He denied fever and chest pain. Clinical examination revealed a febrile patient with heart rate of $80 / \mathrm{min}$, respiratory rate of $22 / \mathrm{min}$ and $\mathrm{SpO} 2$ of $96 \%$ breathing on supplemental oxygen of Fi02 50\%. Bilateral leg edema was present and lung auscultation revealed widespread coarse crepitations. Cardiovascular and abdominal examination was unremarkable. Chest X-Ray (sitting film) showed bilateral alveolar infiltrates in the mid and lower zones with blunting of the right costophrenic angle. Serial ECG and cardiac enzymes were unremarkable. Blood investigations revealed: NT-proBNP 6488 pg/ml $(\mathrm{N}<100)$, Hemoglobin $11 \mathrm{~g} / \mathrm{dl}$, White counts 15.7×10(9)/l, Platelet $41 \times 10(9) / \mathrm{L}$, normal PTT \& APTT, CRP 78.9mg/L

\begin{tabular}{|c|c|c|c|}
\hline & Case 1 & Case 2 & Case 3 \\
\hline Gender & Male & Female & Female \\
\hline Age & 85 & 41 & 54 \\
\hline $\begin{array}{l}\text { CUS* and } \\
\text { Doppler } \\
\text { studies }\end{array}$ & $\begin{array}{l}\text { Floating thrombus in the } \\
\text { right external iliac vein } \\
\text { and the proximal end of } \\
\text { the common femoral vein } \\
\text { which was completely } \\
\text { thrombotic. }\end{array}$ & $\begin{array}{l}\text { Acute right femoral } \\
\text { vein thrombosis }\end{array}$ & $\begin{array}{l}\text { Acute thrombosis } \\
\text { in the mid to distal } \\
\text { left popliteal vein }\end{array}$ \\
\hline Onset of $\mathrm{PE}^{*}$ & 1 hour after CUS & $\begin{array}{l}\text { Immediately after } \\
\text { completion of CUS }\end{array}$ & $\begin{array}{l}\text { Immediately after } \\
\text { leg massage }\end{array}$ \\
\hline $\mathrm{CT}^{*}$ findings & & $\begin{array}{l}\text { Acute filling defects } \\
\text { in the left main } \\
\text { pulmonary artery }\end{array}$ & $\begin{array}{l}\text { Filling defects in } \\
\text { the right upper, } \\
\text { middle and lower } \\
\text { lobar extending to } \\
\text { segmental arteries }\end{array}$ \\
\hline Outcome & Fatal & \multicolumn{2}{|c|}{ Discharged well with anticoagulation } \\
\hline
\end{tabular}

*CUS: Compression Ultrasonography; PE: Pulmonary Thromboembolism; CT: Computed Tomography of the thorax

Table 1: Summary of the three cases.
$(\mathrm{N}<8.8)$, Creatinine $174 \mu \mathrm{mol} / \mathrm{L}$, Protein $58 \mathrm{~g} / \mathrm{L}$, Albumin $27 \mathrm{~g} / \mathrm{L}$. The Urinary Protein Creatinine ratio was $10.52 \mathrm{~g}$. He was referred to the hematologist and the nephrologist for further evaluation.

The patient improved with intravenous Frusemide and Moxifloxacin. On his 4th day of hospitalization, his right lower limb was noted to be bigger than the left. Empiric parental anticoagulation was not started as the patient had hemopytsis and thrombocytopenia. An ultrasonography scan (compression ultrasonography with Doppler study) of the right lower limb was performed 6 hours later, unfortunately the patient collapsed suddenly while talking to his relatives 1 hour after the scan. Despite aggressive cardiopulmonary resuscitation the patient remained in asystole. The ultrasonography scan report returned as: Thrombosis of the entire right common femoral vein and floating thrombus in the right external iliac vein and the proximal end of the common femoral vein (Figure 1).

\section{Case 2}

A 41 year old Chinese female was hospitalized for suspected right lower limb DVT. Her vital signs were normal and she underwent a lower limb ultrasonography (compression ultrasonography with Doppler study) the next day. In the vascular ultrasonography room, she became acutely tachypneic and $\mathrm{SpO} 2$ was $80 \%$ on room air just after completion of ultrasonography which confirmed acute right femoral vein thrombosis. She required supplemental oxygen via intranasal cannula at flow rate of $5 \mathrm{~L} / \mathrm{min}$ to maintain $\mathrm{SpO} 2$ above $92 \%$ and was transferred to the intensive care unit. She was started immediately with parental heparin and an urgent computed tomography (CT) thorax scan done showed acute filling defects in the left main pulmonary artery.

\section{Case 3}

A 54 year old Chinese lady had lower limb aches for a couple of days and went to a parlor for a leg massage. Immediately after the massage, upon standing up, she had acute giddiness, dyspnea, chest tightness and diaphoresis. Her first recorded vital signs taken by the attending paramedics were: blood pressure $77 / 46 \mathrm{mmHg}$, pulse rate $100 / \mathrm{min}$ and SpO2 95\% on facemask FiO2 28\%. Lower limb ultrasonography and CT thorax scan performed in the hospital showed acute thrombosis in the mid to distal left popliteal vein and filling defects in the right

*Corresponding author: Anne AL Hsu, Department of Respiratory \& Critical Care Medicine, 20 College Road, Academia, Level 3, S169856, Singapore, Tel: 65-3214700; E-mail: anne.hsu.a.l@sgh.com.sg

Received October 22, 2013; Accepted December 16, 2013; Published December 20, 2013

Citation: Lee, Hsu AAL (2013) Pulmonary Embolism-A Mechanical Compression Effect on Lower Limb Deep Venous Thrombosis. J Blood Disorders Transf 5: 183 doi: 10.4172/2155-9864.1000183

Copyright: () 2013 Lee. This is an open-access article distributed under the terms of the Creative Commons Attribution License, which permits unrestricted use, distribution, and reproduction in any medium, provided the original author and source are credited. 


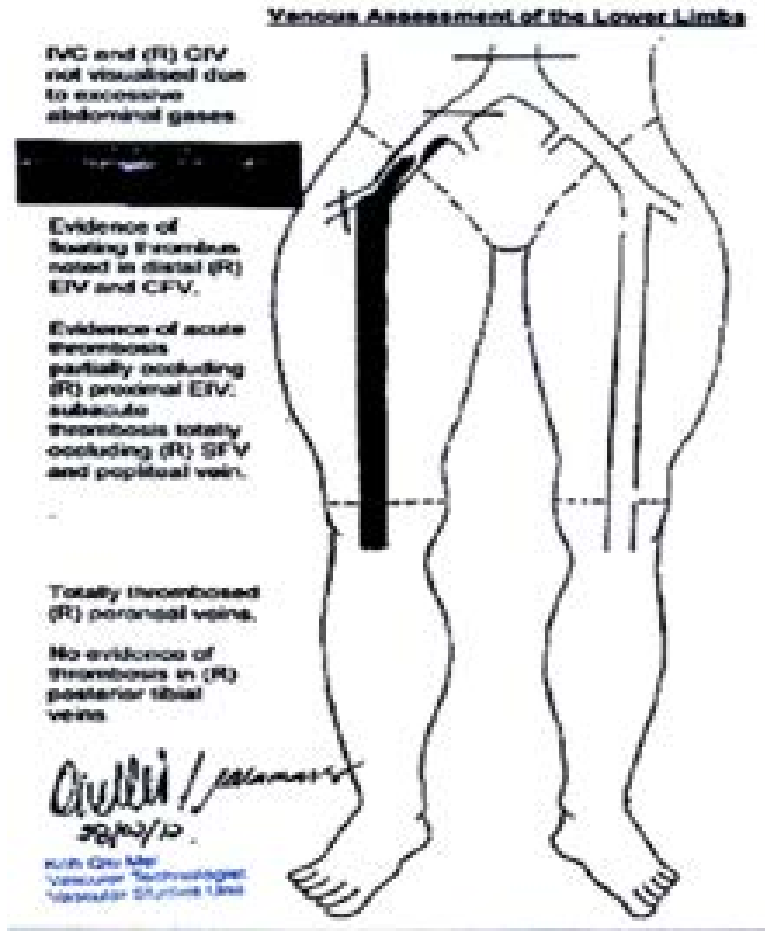

Figure 1: The ultrasonography scan reported thrombosis of the entire right common femoral vein and floating thrombus in the right external iliac vein and the proximal end of the common femoral vein.

upper, middle and lower lobar extending to segmental arteries respectively. There was also CT evidence of right ventricular strain. Further evaluation for hypercoaguable state and CT abdomen and pelvis scan were normal. The patient was treated with anticoagulants and discharged well.

\section{Discussion}

To the best of our knowledge, this is the first report in the medical literature on 3 cases illustrating the detrimental consequence of mechanical compression effect on lower limb DVT.

In the first case, the relative immobilization of an elderly patient due to acute illness and depleting the circulatory fluid in the presence of proteinuria in the Nephrotic range are all risk factors of DVT. The size discrepancy of his lower limbs was noted only after he was treated with diuretics on his 4th day of admission and CUS with Doppler studies was performed within 6 hours of diagnosis. Unfortunately, the patient sustained an acute cardiorespiratory arrest within an hour of the diagnostic test. Although post-mortem was not done, the temporal clinical scenario was consistent with a fatal PE secondary to a floating thrombus in the common femoral vein extending into the iliac vein. The appearance of a FFT on B-mode and color Doppler ultrasonography is impressive as evidenced by the long thrombus 'floating in' the venous lumen and surrounded by moving blood, separating it from the wall. The compression test for vein incompressibility and more likely the dynamic test that accelerates venous flow when the muscles upstream from the ultrasound probe is compressed may have contributed to the fragmentation of the floating clot resulting in fatal PE in this patient. This probably was also the cause of PE of the second case except that the floating clot was not visualized on the ultrasonography. Fragmentation of the femoral vein clot could have happened during the compression and dynamic tests resulting in acute embolism to the pulmonary circulation immediately after completion of the test. Compression Ultrasonography (CUS) is the gold standard for routine diagnosis of deep venous thrombosis [3]. Vein incompressibility on the compression test is the most widely used criterion of the positive diagnosis of DVT: the vein can no longer be collapsed by moderate pressure with the ultrasound probe because of the presence of the thrombus. Using Doppler sonography, vein patency can be evaluated with dynamic tests that increase or accelerate venous flow: compression of muscles upstream from the probe or limb rising produces enhanced Doppler signals in normal veins. A free-floating thrombus (FFT) may be detected in $10-26 \%$ of thrombi detected with ultrasound and is considered a risk factor for pulmonary embolism [3]. Few cases where dislodged FFT caused PE have been reported [4]. However, one prospective study of 95 cases found that FFT occurs in almost 70 percent of patients with proximal $\mathrm{DVT}^{2}$ and no higher risk for PE was observed in the FFT group treated with heparin and early warfarin administration. Endovascular intervention and deep vein ligation or plication with or without partial thrombectomy of FFT has been reported with success in the prevention of PE [5].

In the last case, the middle aged lady had acute PE from fragmentation of the left lower limb DVT with residual thrombosis seen on in the mid to distal left popliteal vein evident on ultrasonography of the lower limbs done about a day after her leg massage eat the parlor. It is conceivable that the mechanical repetitive compression on the left lower limb during the massage may have resulted in the fragmentation and embolization of thrombus in the proximal deep vein.

\section{Conclusions}

Majority of pulmonary thromboembolism (PE) results from clot fragmentation of lower limbdeep vein thrombosis (DVT). The learning points from these 3 cases are:

1) High index of suspicious of DVT is paramount. Meticulous clinical measurement is required to detect clinical lower limb DVT in patient with bilateral limb edema due to fluid overload state. Earlier diagnosis, the avoidance of excessive pressure of the ultrasound probe, more importantly the omission of dynamic test when a floating clot is detected on compression ultrasonography (CUS) and urgent surgical or endovascular intervention may have prevented the fatal outcome in the first case.

2) Prior to anticoagulation treatment, mechanical compression of the thrombosed vein such as massage, application of compressive stockings or devices, probe compression test for vein incompressibility or dynamic test to accelerate venous flow can contribute to the fragmentation of the clot. During limb ultrasonography, compression and dynamic tests should be used cautiously and not repeated unnecessarily. When evident, other criteria like intraluminal echogenicity may be adequate for the diagnosis of DVT.

3) And therefore one of the pitfalls of CUS is although it is a noninvasive test, it is not absolutely safe.

\section{References}

1. Kearon $C$ (2003) Natural history of venous thromboembolism. Circulation 107 : $122-130$.

2. Pacouret G, Alison D, Pottier JM, Bertrand P, Charbonnier B (1997) Freefloating thrombus and embolic risk in patients with angiographically confirmed proximal deep venous thrombosis. A prospective study. Arch Intern Med 157 305-308. 
Citation: Lee, Hsu AAL (2013) Pulmonary Embolism-A Mechanical Compression Effect on Lower Limb Deep Venous Thrombosis. J Blood Disorders Transf 5: 183. doi: 10.4172/2155-9864.1000183

Page 3 of 3

3. Dauzat M, Laroche JP, Deklunder G, Ayoub J, Quére I, et al. (1997) Diagnosis of acute lower limb deep venous thrombosis with ultrasound: trends and controversies. J Clin Ultrasound 25: 343-358.

4. Brodmann M, Gary T, Hafner F, Tiesenhausen K, Deutschmann H, et al. (2012)
Massive pulmonary embolism caused by internal iliac vein thrombosis with freefloating thrombus formation in the inferior vena cava. Ann Vasc Surg 26: 420.

5. Casian D, Gutsu E, Culiuc V (2010) Extraluminal venous interruption for freefloating thrombus in the deep veins of lower limbs. Chirurgia (Bucur) 105: 361-364.

Citation: Lee, Hsu AAL (2013) Pulmonary Embolism-A Mechanical

Compression Effect on Lower Limb Deep Venous Thrombosis. J Blood Disorders Transf 5: 183. doi: 10.4172/2155-9864.1000183 